Western University

Scholarship@Western

Psychiatry Publications

Psychiatry Department

$12-1-2015$

\title{
Trends in Psychotropic Dispensing Among Older Adults with Dementia Living in Long-Term Care Facilities: 2004-2013.
}

\author{
Akshya Vasudev \\ Salimah Z Shariff \\ Kuan Liu \\ Amer M Burhan \\ Nathan Herrmann
}

See next page for additional authors

Follow this and additional works at: https://ir.lib.uwo.ca/psychiatrypub

Part of the Psychiatry and Psychology Commons

Citation of this paper:

Vasudev, Akshya; Shariff, Salimah Z; Liu, Kuan; Burhan, Amer M; Herrmann, Nathan; Leonard, Sean; and Mamdani, Muhammad, "Trends in Psychotropic Dispensing Among Older Adults with Dementia Living in Long-Term Care Facilities: 2004-2013." (2015). Psychiatry Publications. 30.

https://ir.lib.uwo.ca/psychiatrypub/30 
Authors

Akshya Vasudev, Salimah Z Shariff, Kuan Liu, Amer M Burhan, Nathan Herrmann, Sean Leonard, and Muhammad Mamdani 


\title{
Trends in Psychotropic Dispensing Among Older Adults with Dementia Living in Long-Term Care Facilities: 2004-2013
}

\author{
Akshya Vasudev, M.B.B.S., M.D., M.R.C.Psych., Salimab Z. Shariff, B.Math, Ph.D, \\ Kuan Liu, M.Math, BSc Honours, Amer M. Burban, MBCbB, MScCH, FRCP(C), \\ Natban Hermann, M.D., F.R.C.P(C), Sean Leonard, B.Sc., \\ Mubammad Mamdani, M.P.H., M.A., Pharm.D
}

\begin{abstract}
Objective: Guidelines worldwide have cautioned against the use of antipsychotics as first-line agents to treat neuropsychiatric symptoms of dementia. We aimed to investigate the changes over time in the dispensing of antipsychotics and other psychotropics among older adults with dementia living in long-term care facilities. Methods: We used drug claims data from Ontario, Canada, to calculate quarterly rates of prescription dispensing of six psychotropic drug classes among all elderly ( $\geq 65$ years of age) long-term care residents with dementia from January 1, 2004, to March 31, 2013. Psychotropic drugs were classified into the following categories: atypical and conventional antipsychotics, non-sedative and sedative antidepressants, anti-epileptics, and benzodiazepines. We used time-series analysis to assess trends over time. Results: The study sample increased by $21 \%$ over the 10-year study period, from 49,251 patients to 59,785 patients. The majority of patients (within the range of 75\%-79\%) were dispensed at least one psychotropic medication. At the beginning of the study period atypical antipsychotics (38\%) were the most frequently dispensed psychotropic, followed by benzodiazepines (28\%), non-sedative antidepressants (27\%), sedative antidepressants (17\%), anti-epileptics (7\%), and conventional antipsychotics (3\%). Dispensing of anti-epileptics (2\% increase) and conventional antipsychotics (1\% decrease) displayed modest changes over time, but we observed more pronounced changes in dispensing of benzodiazepines (11\% decrease) and atypical antipsychotics (4\% decrease). Concurrently, we observed a substantial growth in the dispensing of both sedative (15\% increase) and non-sedative ( $9 \%$ increase) antidepressants. The proportion of patients dispensed two or more psychotropic drug classes increased from $42 \%$ in 2004 to $50 \%$ in 2013. Conclusions: Utilization patterns of
\end{abstract}

Received December 16, 2014; revised June 30, 2015; accepted July 7, 2015. From the Division of Geriatric Psychiatry, Department of Psychiatry (AV, AMB), and the Division of Clinical Pharmacology, Department of Medicine (AV), Western University, London, Canada; the Institute for Clinical Evaluative Sciences (SZS, KL, SL, MM), London, Canada; the Li Ka Shing Knowledge Institute of St. Michael's Hospital (MM), Toronto, Canada; and the Institute of Health Policy, Management, and Evaluation, Leslie Dan Faculty of Pharmacy (MM), and the Sunnybrook Health Sciences Centre $(\mathrm{NH})$, University of Toronto, Toronto, Canada. Send correspondence and reprint requests to Dr. Akshya Vasudev, M.B.B.S., M.D., M.R.C.Psych., \#A2-607, Victoria Hospital, London Health Sciences Centre, 800 Commissioners Road East, London, Ontario, Canada, N6A 5W9. e-mail: akshya.vasudev@uwo.ca

Supplemental digital content is available for this article in the HTML and PDF versions of this article on the journal's Web site (www. ajgponline.org).

(c) 2015 American Association for Geriatric Psychiatry

http:/ /dx.doi.org/10.1016/j.jagp.2015.07.001 


\begin{abstract}
psychotropic drugs in institutionalized patients with dementia bave changed over the past decade. Although their use declined slightly over the study period, atypical antipsychotics continue to be used at a high rate. A decline in the use of benzodiazepines along with an increased use of sedative and non-sedative antidepressants suggests that the latter class of drugs is being substituted for the former in the management of neuropsychiatric symptoms. Psychotropic polypharmacy continues to be highly prevalent in these patient samples. (Am J Geriatr Psychiatry 2015; 23:1259-1269)
\end{abstract}

Key Words: Dispensing, antipsychotics, psychotropics, dementia, long-term care

$\mathrm{T}$ wo out of three elderly long-term care residents suffer from dementia ${ }^{1,2}$; of these patients, approximately $80 \%{ }^{3}$ present with neuropsychiatric symptoms (NPS) such as anxiety, depression, agitation, psychological distress, psychosis, and/or insomnia. ${ }^{4}$ Psychotropic medications are often used to manage such symptoms. ${ }^{5}$

In the past decade, numerous drug regulatory agencies and clinical guidelines have cautioned against the use of antipsychotics, either conventional or atypical, to manage NPS; these warnings are based on findings of increased risks with these medications of cerebrovascular events and death. ${ }^{6-12}$ Nonetheless, they continue to be prescribed and dispensed with varying rates around the world (from $7 \%$ to $40 \%) .{ }^{13-19}$ The Canadian dementia guidelines have identified other classes of psychotropics that may be considered instead for the management of NPS; these include antidepressants (sedative and non-sedative), benzodiazepines, anti-epileptics and cognitive enhancers. ${ }^{10}$ These guidelines, however, as well as those from other countries, highlight the variable evidence base for the use of these agents. ${ }^{5,20}$ It may be that each class of psychotropic is being differentially used to target specific NPS. Though not recommended, physicians may prescribe a combination of more than one psychotropic drug class in an attempt to manage the NPS, although the evidence base for this practice is even more limited..$^{21,22}$

Although the dispensing rates of psychotropics in patients with dementia are well documented in the community setting, ${ }^{23,24}$ there are limited reports of their use in the long-term care setting. When compared with dementia patients in the community setting, long-term care patients are older, more frail, and at increased risk of the adverse effects of psychotropic medications; these include potentially dangerous drug interactions between co-dispensed psychotropic medications.

Physicians have become increasingly aware of the risks associated with the use of antipsychotics in the elderly and may be shifting their prescribing to other psychotropics, as single agents or in combination, to manage the NPS in older patients with dementia in long-term care facilities. We assessed the dispensing rate of antipsychotics and other classes of psychotropics in older adults with dementia living in longterm care facilities from 2004 to 2013.

\section{METHODS}

This study was approved by the Sunnybrook Health Sciences Centre research ethics board in Toronto, Ontario.

\section{Study Design and Setting}

We conducted a cross-sectional time-series analysis in Ontario, Canada. Ontario is the most populous province of Canada; at the beginning of 2004 approximately 1.3 million Ontarians were 65 years of age or older. By the end of 2017 this population is expected to grow to over 1.6 million. ${ }^{25}$

\section{Data Source and Study Outcomes}

We used data from a number of linked healthcare databases housed at the Institute of Clinical Evaluative Sciences, Ontario, Canada. These databases included the Registered Persons Database, which contains demographic information on all Ontario residents; the Ontario Health Insurance Plan 
database, which contains information on physician billing claims for inpatient procedures and outpatient physician visits; the Canadian Institutes of Health Information-Discharge Abstract Database, which contains information about hospitalizations; and the Ontario Drug Benefits (ODB) database, which contains information on all medications dispensed for those aged 65 years or older, and identifies whether a patient resides in a long-term care facility. The ODB database has been found to have an error rate of less than $1 \% .^{26}$

\section{Cohort Formation}

For the purpose of this study, we divided each calendar year into four quarters (three-month periods; quarter 1 [Q1]: January to March, Q2: April to June, Q3: July to September, Q4: October to December). Data collection occurred from January 1, 2004, through March 31, 2013, generating a total of 37 quarters. For each quarter, the study sample comprised all residents of Ontario aged 66 years and above living in a long-term care home with a diagnosis of dementia. Patients were identified as having dementia if in the 5 years prior to the start of the interval they had a hospitalization involving a diagnosis of dementia (International Classification of Diseases, Tenth Revision [ICD-10] codes: F00, F01, F02, F03, F05.1, F06.5, F06.6, F06.8, F06.9, G30, G31, R54) or a physician-documented outpatient diagnosis for dementia (ICD-9 codes: 290, 331, 797). We selected a combination of both inpatient and outpatient codes to maximize the sensitivity of diagnoses; these codes have been used in previous large-scale database studies. $^{27-29}$ To determine long-term care residency status, we reviewed data from the most recently filled prescription in the one year prior to the start of each quarter. We did not include patients in their first year of prescription-drug coverage (65 years of age) to allow for a one-year look-back. Figure 1 outlines additional exclusion criteria and an example of how each cohort was developed.

\section{Cohort Characteristics}

Three quarters were selected a priori to examine patient characteristics at the beginning (January to March, 2004), middle (January to March, 2009) and end (January to March 2013) of the study period. In addition to demographic characteristics, we used hospitalization records from the five years prior to the start of each quarter to characterize their dementia diagnosis and generate a Charlson comorbidity in$\operatorname{dex}^{30}$ validated for administrative claims databases ${ }^{31}$ (list of comorbidities presented in Table 1).

\section{Prescription-Level Monitoring}

For every quarter, we identified all prescriptions for the following psychotropic drug classes: atypical and conventional antipsychotics, non-sedative and sedative antidepressants, anti-epileptics, and benzodiazepines (specific drugs are listed in Appendix 1). We selected these medications as they are frequently dispensed for the management of the NPS of dementia. The rate of dispensing of each drug class was calculated quarterly by summing the number of patients dispensed a prescription for that drug class divided by the total number of patients in that quarter. Similarly, the rate of dispensing combination psychotropics was assessed by counting the number of patients who were dispensed with two or more unique psychotropic drug classes in the quarter being studied divided by the total number of patients in that quarter. Medications that did not have universal provincial coverage throughout the study period, or where the total count of prescriptions for the sample was less than 5 , were excluded.

\section{Statistical Analysis}

To assess trends in the use of psychotropics, data was analyzed through time-series analysis ${ }^{32}$ using exponential smoothing models. Time-series analyses are well-established methods that use a collection of techniques for modeling autocorrelations in temporally sequenced data. ${ }^{32}$ Schwarz-Bayesian criteria were used to assess the best model fit. The level, trend, damping, and seasonality smoothing weights were determined to optimize the fit of the model. The statistical significance of the smoothing weights was tested using $\mathrm{t}$ tests. Stationarity was determined with the use of the autocorrelation function and the augmented Dickey-Fuller test. ${ }^{33}$ The autocorrelation, partial autocorrelation, and inverse autocorrelation functions were further calculated for model parameter appropriateness and seasonality. The presence of white noise was assessed by examining the autocorrelations at various lag points using the Ljung-Box $\chi^{2}$ statistic. $^{34}$ Additionally, on a post hoc basis, we 
FIGURE 1. Illustration of development of one sub-cohort, Quarter 12004.

$$
\begin{aligned}
& \text { Number of patients on Jan } 1^{\text {st }} 2004 \text { who had dementia diagnosis within the previous } 5 \text { years. } \\
& n=282,134
\end{aligned}
$$$$
\begin{aligned}
& \text { Number Excluded, } n=232,883 \\
& \text { Patients with missing age or sex identification, } n=16 \\
& \text { Patients with death on or before the beginning of each time interval, } n=111,271 \\
& \text { Patients with a non-Ontario residence at the beginning of each time interval, } n=1,196 \\
& \text { Patients with age }<66 \text { at the beginning of each time interval, } n=33,859 \\
& \text { Patients with no ODB drug prescription in the previous } 1 \text { year to the beginning of each interval, } \\
& n=5,419 \\
& \text { Patients not living in a long-term care (LTC) facility as identified by their most recent ODB claim, } \\
& n=81,122
\end{aligned}
$$

used exponential smoothing models to forecast the prescription rate of select psychotropic classes that exhibited impactful changes in dispensing during the 10-year study period (2004 to 2013); rates were forecasted to 2017. For assessment of differences in baseline characteristics across the selected time points, we conducted the $\chi^{2}$ test to examine the changes in proportion of categorical variables and Kruskal-Wallis test to examine the changes in medians of continuous variables. SAS software package for Windows, Version 9.3 (SAS Institute, Inc., Cary, $\mathrm{NC}$,) was used for all statistical analyses.

\section{RESULTS}

\section{Dementia Patients in Ontario Long-Term Care Homes}

The number of patients included in the study increased by 21\% from 49,251 in Q1 2004 to 59,785 in
Q1 2013. The proportion of women reduced from $74 \%$ in Q1 $2004(36,204$ of 49,251$)$ to $71 \%(42,739$ of $\left.59,785, \chi^{2}=55.74, \mathrm{df}=2, \mathrm{p}<0.001\right)$. The median age increased from 85 years to 86 years (Kruskal-Wallis Test, $\left.\chi^{2}=556.24, \mathrm{df}=2, \mathrm{p}<0.0001\right)$ over the study period. Alzheimer dementia was the most commonly diagnosed form of dementia, (98\%: 47,903 of 49,251 in Q1 2004 and 58,237 of 59,785 in Q1 2013, $\chi^{2}=13.33$, $\mathrm{df}=2, \mathrm{p}=0.0013)$. The baseline characteristics of these patients did not appear to change considerably over time (Table 1).

\section{Dispensing Changes}

The proportion of patients dispensed each psychotropic drug class from January 1, 2004, to March 31, 2013, is presented in Figure 2. Further statistical details of all model results presented herein are available in Table 2. Among the classes of psychotropics included in the analyses, the proportion of patients on anti-epileptics (2 percentage point 
TABLE 1. Clinical and Demographic Characteristics of the Study Sample

\begin{tabular}{|c|c|c|c|c|c|c|}
\hline & \multicolumn{2}{|c|}{ January 1, 2004} & \multicolumn{2}{|c|}{ January 1, 2009} & \multicolumn{2}{|c|}{ January 1, 2013} \\
\hline & $\begin{array}{c}\text { Total } \\
\mathbf{N}=49,251\end{array}$ & $\%$ & $\begin{array}{c}\text { Total } \\
\mathbf{N}=\mathbf{5 6 , 7 2 3}\end{array}$ & $\%$ & $\begin{array}{c}\text { Total } \\
\mathbf{N}=\mathbf{5 9 , 7 8 5}\end{array}$ & $\%$ \\
\hline \multicolumn{7}{|l|}{ Demographics } \\
\hline \multicolumn{7}{|l|}{ Age (years) } \\
\hline Mean (SD) & $84.41(7.35)$ & & $84.92(7.24)$ & & $85.36(7.39)$ & \\
\hline Median (IQR) & $85(80-90)$ & & $85(80-90)$ & & $86(81-91)$ & \\
\hline $66-75.9$ & 6,127 & 12.44 & 6,154 & 10.85 & 6,463 & 10.81 \\
\hline $76-85.9$ & 20,433 & 41.49 & 22,525 & 39.71 & 21,456 & 35.89 \\
\hline $86-95.9$ & 19,850 & 40.30 & 24,567 & 43.31 & 27,751 & 46.42 \\
\hline $96+$ & 2,841 & 5.77 & 3,477 & 6.13 & 4,115 & 6.88 \\
\hline Sex - Female, $N$ & 36,204 & 73.51 & 41,157 & 72.56 & 42,739 & 71.49 \\
\hline \multicolumn{7}{|l|}{ Diagnosis of type of dementia, $\mathrm{N}$} \\
\hline Alzheimer dementia & 47,903 & 97.26 & 55,350 & 97.58 & 58,327 & 97.56 \\
\hline Vascular dementia & 1,621 & 3.29 & 1,454 & 2.56 & 1,366 & 2.28 \\
\hline Other dementias & 8,020 & 16.28 & 4,151 & 7.32 & 3,890 & 6.51 \\
\hline Unspecified dementias & 5,627 & 11.43 & 11,829 & 20.85 & 14,580 & 24.39 \\
\hline Organic brain syndrome & 305 & 0.62 & 257 & 0.45 & 154 & 0.26 \\
\hline Delirium superimposed on dementia & 1,435 & 2.91 & 1,949 & 3.44 & 3,201 & 5.35 \\
\hline \multicolumn{7}{|c|}{ Comorbidities (Charlson Comorbidity Index Categorizations), $\mathrm{N}$} \\
\hline AMI & 3,003 & 6.10 & 2,831 & 4.99 & 2,776 & 4.64 \\
\hline $\mathrm{CHF}$ & 5,326 & 10.81 & 5,061 & 8.92 & 5,151 & 8.62 \\
\hline PVD & 1,750 & 3.55 & 1,479 & 2.61 & 1,406 & 2.35 \\
\hline CVD & 5,506 & 11.18 & 4,402 & 7.76 & 3,996 & 6.68 \\
\hline COPD / Other respiratory disease & 4,780 & 9.71 & 3,963 & 6.99 & 4,119 & 6.89 \\
\hline Rheumatologic disease & 668 & 1.36 & 491 & 0.87 & 528 & 0.88 \\
\hline Digestive ulcer & 682 & 1.38 & 641 & 1.13 & 693 & 1.16 \\
\hline Mild liver disease & 366 & 0.74 & 242 & 0.43 & 272 & 0.45 \\
\hline Diabetes & 5,459 & 11.08 & 3,994 & 7.04 & 3,777 & 6.32 \\
\hline Diabetes with chronic complications & 1,018 & 2.07 & 5,406 & 9.53 & 8,061 & 13.48 \\
\hline Hemi or paraplegia & 2,106 & 4.28 & 1,775 & 3.13 & 1,680 & 2.81 \\
\hline Renal disease & 2,069 & 4.20 & 3,348 & 5.90 & 3,273 & 5.47 \\
\hline Primary cancer & 991 & 2.01 & 1,278 & 2.25 & 1,406 & 2.35 \\
\hline Moderate / Severe liver disease & 83 & 0.17 & 111 & 0.20 & 119 & 0.20 \\
\hline Metastatic cancer & 334 & 0.68 & 337 & 0.59 & 407 & 0.68 \\
\hline HIV infection & $\leq 5$ & $<0.01$ & $\leq 5$ & $<0.01$ & $\leq 5$ & $<0.01$ \\
\hline \multicolumn{7}{|l|}{ Charlson Index (Weighted Sum) } \\
\hline Mean (SD) & $1.69(1.09)$ & & $1.62(1.02)$ & & $1.61(0.99)$ & \\
\hline Median (IQR) & $1(1-2)$ & & $1(1-2)$ & & $1(1-2)$ & \\
\hline 1 & 30,074 & 61.06 & 35,940 & 63.36 & 37,018 & 61.92 \\
\hline 2 & 10,188 & 20.69 & 11,756 & 20.73 & 13,369 & 22.36 \\
\hline 3 & 5,124 & 10.40 & 5,421 & 9.56 & 5,721 & 9.57 \\
\hline $4+$ & 3,865 & 7.85 & 3,606 & 6.36 & 3,677 & 6.15 \\
\hline
\end{tabular}

Notes: AMI: acute myocardial infarction; CHF: congestive heart failure; CVD: cerebrovascular disease; COPD: chronic obstructive pulmonary disease; HIV: human immunodeficiency virus; IQR: interquartile range; PVD: peripheral vascular disease; SD: standard deviation.

increase: 3,669 of 49,251 = 7\% in Q1 2004 and 5,450 of $59,785=9 \%$ in Q1 2013) and conventional antipsychotics (1 percentage point decrease: 1,784 of $49,251=3 \%$ in Q1 2004 and 1,247 of 59,785 = 2\% in Q1 2013) demonstrated modest changes over the study period. We found a larger reduction in the proportion of the patients dispensed benzodiazepines (11 percentage point decrease: 13,835 of $49,251=28 \%$ in Q1 2004 to 10,103 of $59,785=17 \%$ in Q1 2013) and atypical antipsychotics (4 percentage point decrease: 18,700 of $49,251=38 \%$ in Q1 2004 to
20,082 of $59,785=34 \%$ in Q1 2013). There was a concurrent large change in proportion of patients dispensed a sedative antidepressant (15 percentage point increase: 8,245 of 49,251 $=16 \%$ in Q1 2004 and 18,277 of $59,785=31 \%$ in Q1 2013), as well as non-sedative antidepressants (9 percentage point increase: 13,053 of $49,251=27 \%$ in Q1 2004 and 21,512 of $59,785=36 \%$ in Q1 2013).

Overall, the proportion of patients dispensed any psychotropic drug increased from 75\% in Q1 2004 $(36,825$ of 49,251$)$ to $79 \%$ in Q1 $2013(47,330$ of 
FIGURE 2. Proportion of patients (percentage) dispensed six classes of psychotropics from January 1, 2004 to March 31,2013 among patients with dementia in long-term care facilities in Ontario, Canada.
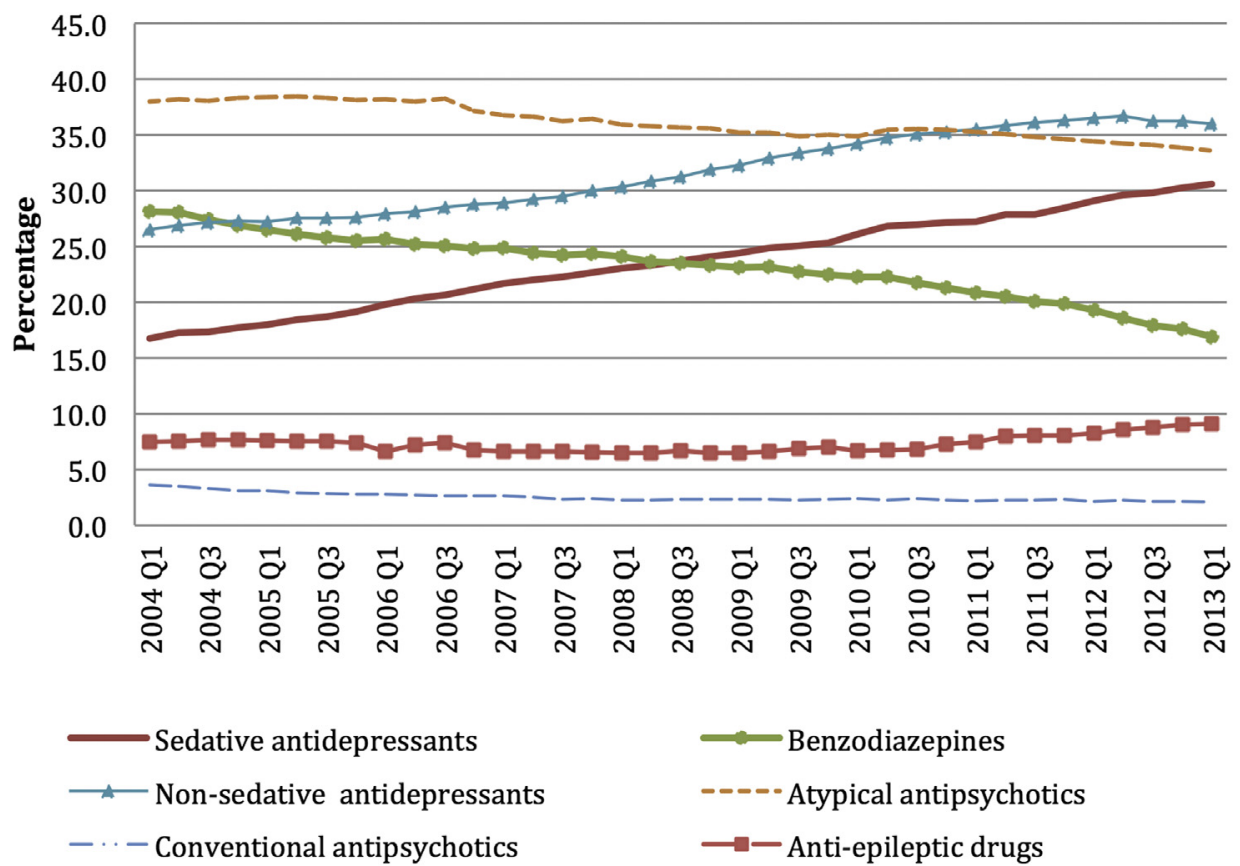

59,785). Over the same period, the proportion of study patients on two or more different classes of psychotropics increased from $42 \%(21,019$ of 49,251$)$ to $50 \%(29,928$ of 59,785$)$ (Fig. 3).

\section{Projection of Dispensing Proportions}

Based on the three psychotropic classes that exhibited the largest changes during the past decade (2004-2013), over the next four years (2014-2017) the following projections were made: The proportion of patients dispensed atypical antipsychotics may decrease from $34 \%$ to $31 \%$ and benzodiazepine use may decrease from $17 \%$ to $8 \%$ of patients while the proportion dispensed sedative antidepressant is expected to continue increasing from $32 \%$ to $36 \%$ of patients (Fig. 4).

\section{DISCUSSION}

This study provides an analysis of trends over time (2004-2013) in the dispensing of six classes of psychotropics for the treatment of NPS among frail, older patients with dementia residing in long-term care facilities in Ontario, Canada. Over the past decade the overall psychotropic use has remained stable, with nearly three-quarters of all patients dispensed at least one medication. We observed a marginal but statistically significant decline in the proportion of patients dispensed antipsychotics (atypical and conventional) and anti-epileptics, and a more dramatic decline in proportion of patients on benzodiazepines was observed. Conversely, use of sedative and non-sedative antidepressants increased markedly. We also observed an overall increase in psychotropic combination therapy.

\section{Interpretation}

Among other findings, we saw a relatively high and steady usage of antipsychotics contrasting with a declining use of benzodiazepines; this pattern has been shown in previous studies. Those studies, however, did not examine psychotropic drug use in patients living in long-term care homes. ${ }^{6,19,35,36}$ The ongoing and projected high dispensing of atypical antipsychotics is of concern in the context of multiple warnings around cerebrovascular events and death associated with these 
TABLE 2. Statistical Details of Best-Fitting Smoothing Models

\begin{tabular}{|c|c|c|c|c|c|c|c|}
\hline Drug Class & Best Fitting Model & $\begin{array}{c}\text { t Test } \\
\text { Statistic }\end{array}$ & $\begin{array}{c}\text { Degrees } \\
\quad \text { of } \\
\text { Freedom }\end{array}$ & $\begin{array}{l}\text { Mean } \\
\text { Square } \\
\text { Error }\end{array}$ & $\begin{array}{c}\mathbf{R}^{2} \\
\text { Value }\end{array}$ & $\begin{array}{c}\text { Schwarz } \\
\text { Bayesian } \\
\text { Information } \\
\text { Criterion } \\
\text { (BIC) }\end{array}$ & p Value \\
\hline $\begin{array}{l}\text { Sedative } \\
\text { antidepressants }\end{array}$ & Winter Additive & 7.9802 & 34 & 0.03259 & 0.998 & -115.84848 & $<0.001$ \\
\hline $\begin{array}{l}\text { Cognitive } \\
\text { enhancers }\end{array}$ & Winter Additive & 9.1833 & 34 & 0.02068 & 0.999 & -132.67327 & $<0.001$ \\
\hline Non-sedative antidepressants & $\begin{array}{l}\text { Linear (Holt) } \\
\text { Exponential Smoothing }\end{array}$ & 5.4507 & 35 & 0.02886 & 0.998 & -123.95571 & $<0.001$ \\
\hline Benzodiazepines & $\begin{array}{l}\text { Linear (Holt) } \\
\text { Exponential Smoothing }\end{array}$ & 6.3588 & 35 & 0.04548 & 0.995 & -107.12739 & $<0.001$ \\
\hline Atypical antipsychotics & $\begin{array}{l}\text { Log Double (Brown) } \\
\text { Exponential Smoothing }\end{array}$ & 10.3349 & 35 & 0.07874 & 0.966 & -90.42799 & $<0.001$ \\
\hline Conventional antipsychotics & $\begin{array}{l}\text { Log Linear (Holt) } \\
\text { Exponential Smoothing }\end{array}$ & 5.6427 & 35 & 0.0054253 & 0.964 & -185.79540 & $<0.001$ \\
\hline Anti-epileptic drugs & $\begin{array}{l}\text { Log Double (Brown) } \\
\text { Exponential Smoothing }\end{array}$ & 8.2677 & 35 & 0.06551 & 0.881 & -97.23334 & $<0.001$ \\
\hline $\begin{array}{l}\text { Any one class of psychotropic } \\
\text { Two or more different classes }\end{array}$ & $\begin{array}{l}\text { Winter Additive } \\
\text { Winter Additive }\end{array}$ & $\begin{array}{l}4.3938 \\
7.0046\end{array}$ & $\begin{array}{l}34 \\
34\end{array}$ & $\begin{array}{l}0.03247 \\
0.07041\end{array}$ & $\begin{array}{l}0.987 \\
0.989\end{array}$ & $\begin{array}{r}-115.98170 \\
-87.34621\end{array}$ & $\begin{array}{r}0.001 \\
<0.001\end{array}$ \\
\hline
\end{tabular}
of psychotropics

Note: $\mathrm{p}$ values test the null hypothesis that the level (intercept) smoothing weight equals 0.

FIGURE 3. Proportion of patients on one or more classes of psychotropics among patients with dementia living in long-term care facilities in Ontario, Canada, from 2004 to 2013.

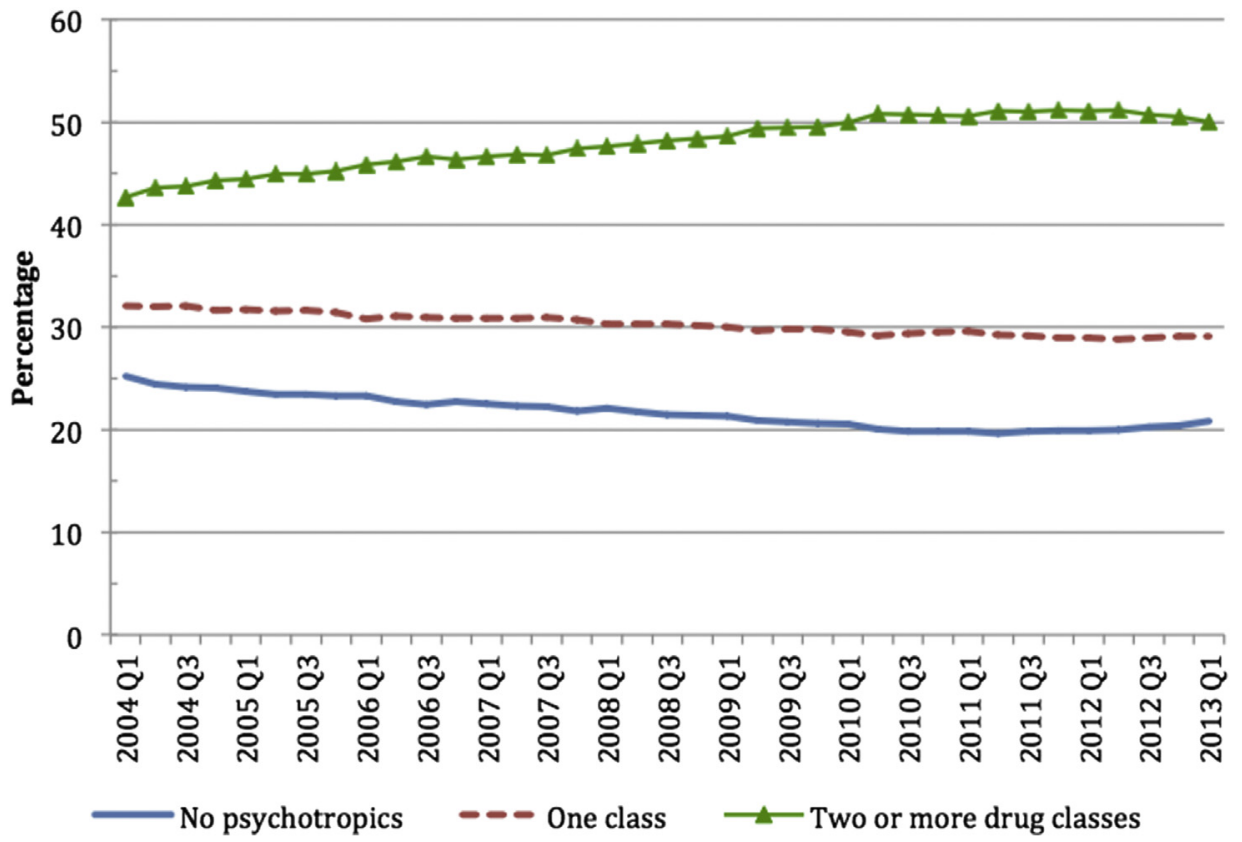

agents. $^{6-12}$ On the other hand, the declining use of benzodiazepines is reassuring, as this would have likely resulted in fewer incidents of falls, fractures, and subsequent hospital admissions over the past decade. ${ }^{37}$
This study highlights an increased use of nonsedative antidepressants. This trend needs to be viewed in the context of the Canadian Consensus Conference on the Diagnosis and Treatment of 
FIGURE 4. Actual and projected use of [A] sedative antidepressants, [B] atypical antipsychotics, and [C] benzodiazepines among patients with dementia living in long-term care facilities in Ontario, Canada. from 2004 to 2013.
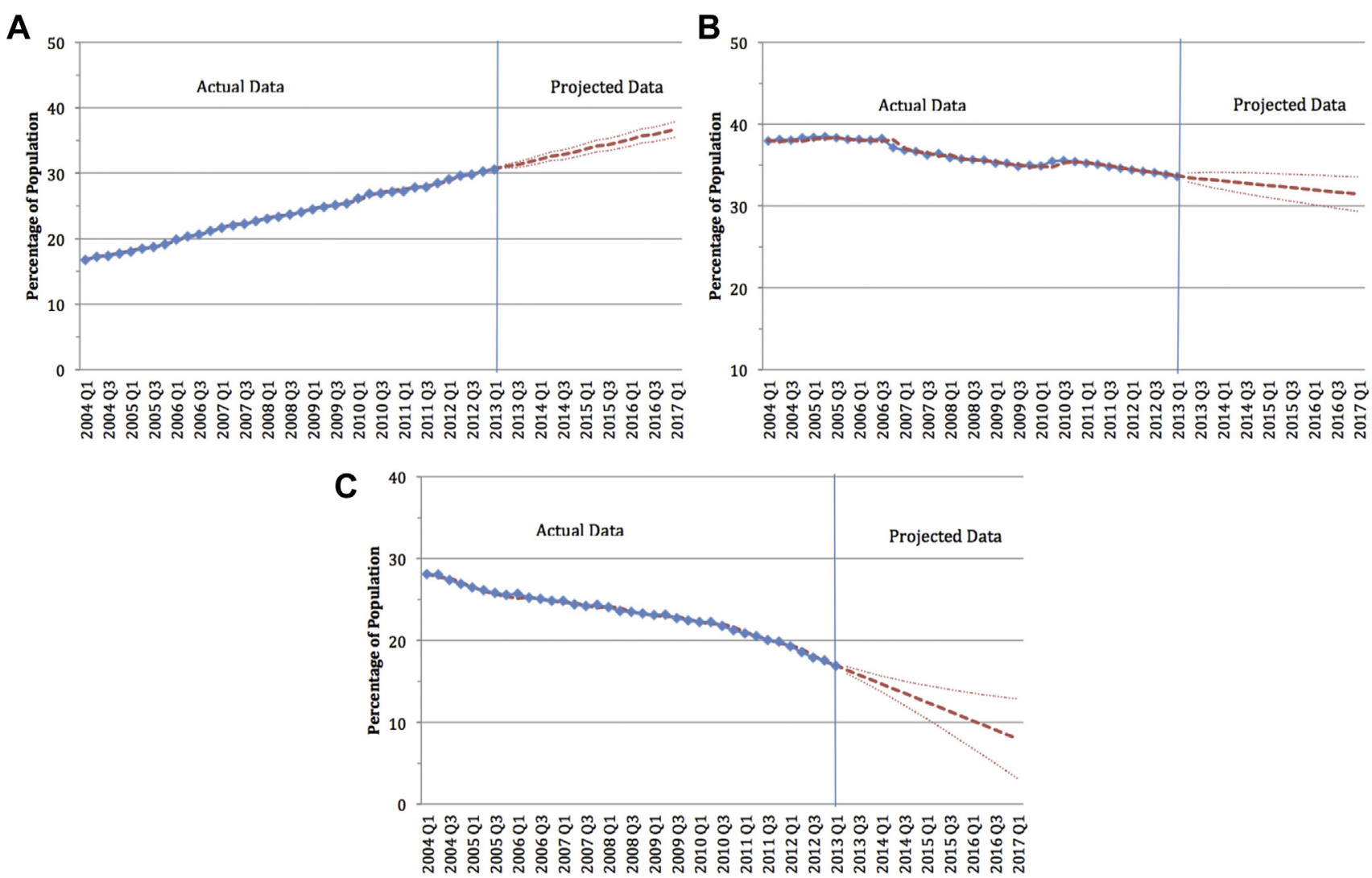

Notes: The number of actual prescriptions from Q1 2004 to Q1 2013 are depicted by solid blue squares; the predicted prescriptions are depicted by dotted red lines; 95\% confidence intervals around the projected prescriptions beyond Q1 2013 are presented as red dashed lines/error bars. The vertical blue line denotes the beginning of the period of projected data.

Dementia (CCCDTD), ${ }^{12}$ which acknowledges that the use of antidepressants for managing affective disturbances associated with dementia are an option, but not a firm recommendation. These recommendations were partly based on a recent non-industrysponsored large sample study, which failed to find any difference in the effects of sertraline, mirtazapine, or placebo in a randomized controlled setting. ${ }^{38}$ Nevertheless, a more recent study focusing on the management of agitation in the context of dementia found some benefits with citalopram, a non-sedative antidepressant, ${ }^{39}$ although there were adverse effects on cognition and the cardiovascular system.

We also found that long-term care residents with dementia are increasingly being dispensed sedative antidepressants, which include medications such as trazodone, mirtazapine, and tricyclic antidepressants. We suspect that the increased use of sedative antidepressants is for the promotion of sedation, the treatment of comorbid depression, or to manage the agitation or aggression associated with dementia. Because of the large sample-based nature of this study we are unable to confirm any of the above reasons for this usage. Although not specifically tested, however, the converse increase in antidepressant dispensing with declines in benzodiazepine dispensing suggests that prescribers may be substituting benzodiazepines with antidepressants in an attempt to manage NPS. The ongoing and projected increase in the usage of sedative antidepressants is of possible concern as the safety and effectiveness of these agents is based only on smallscale studies. ${ }^{40-42}$ For instance, the administration 
of mirtazapine for the treatment of depressive symptoms in outpatients with dementia led to reports of excessive drowsiness and sedation in $44 \%$ of patients. ${ }^{24}$ Such symptoms could increase the risk of falls, injuries, fractures, and mortality. Therefore, the use of sedative antidepressants for the NPS of dementia needs to be further investigated.

One of the other recommendations of the CCCDTD was to reduce reliance on the usage of anti-epileptics, particularly valproate, as it has been associated with significant toxicity, accelerated brain volume loss, greater cognitive impairment, and a similar risk of mortality as that previously found with antipsychotics. ${ }^{10}$ The ongoing use of such agents is therefore of some concern.

We also examined the extent of the dispensing of combination psychotropic medications; such usage may further increase the risk of cognitive impairment, orthostatic hypotension, falls, and skeletal fractures. ${ }^{43}$ In order to compare psychotropic prescription rates we divided the patients into two groups: those on one, and those on two or more classes of agents. We did not attempt to categorize whether certain psychotropic combination prescriptions were pharmacologically appropriate or not, as there is an inadequate evidence base for taking this approach. ${ }^{44}$ We do, however, recognize that physicians caring for patients with dementia in long-term care settings are often faced with the dilemma of balancing the use of psychotropic combination therapy with its associated risks. These physicians must also take into account the need to reduce the anxiety in staff and other residents caused by patients' calling out, agitation, hallucinations, and other NPS associated with dementia. ${ }^{45}$ Fortunately, it is possible to reduce potentially inappropriate combination therapy through concerted multidisciplinary and frequent medication reviews. $^{46}$

In light of the limitations posed by pharmacological treatments, nonpharmacological interventions using music or environmental manipulation may provide alternatives for the management of NPS. There is some evidence that such interventions can be of benefit if tailored to the individual patient, and if healthcare providers are given adequate support to offer such treatments. ${ }^{47}$ High-quality large-scale studies for assessing the efficacy of such therapies have yet to be performed. ${ }^{48}$

\section{Study Limitations}

There are several limitations to the present study. First, this study was retrospective in nature and hence suffers from inherent biases associated with such a design. Second, healthcare databases do not code dementias using the more stringent standardized diagnostic criteria for characterizing the type or severity of dementia as suggested by the National Institute on Aging/Alzheimer's Association Diagnostic Guidelines for Alzheimer's Disease; such diagnoses are typically used for characterizing patients in prospective randomized controlled trials. Our approach of using either an outpatient, or an inpatient physician coding, however, would offer increased sensitivity, without compromising on specificity of diagnosis. ${ }^{27-29}$ Third, we were unable to accurately capture the dispensing of cognitive enhancers as they were not universally covered under the drug compensation plan in Ontario (ODB) during the study period. Fourth, we did not characterize the usage of individual psychotropic within each drug class, as this would have led to an inordinately large amount of data, making it difficult to interpret the results. Fifth, additional clinical information is required to better characterize patients; this better understanding of a patient's needs will help to identify appropriate drug use, and to develop a structured approach for dealing with polymedicated patients. Finally, the extrapolated prediction-model- projected psychotropic usages are based on assumptions inherent to the model used, and as such do not account for outside variables that may influence future trends such as changes in formulary coverage, introduction of new medications, or changes in practice guidelines.

\section{Conclusions and Implications}

This study outlines current trends in the dispensing of various classes of psychotropics for the treatment of NPS in patients with dementia residing in long-term care facilities in Ontario, Canada. The results suggest a high prevalence of sedative antidepressant usage with a concomitant decline in the usage of antipsychotics and benzodiazepines, suggesting that the former have supplanted the latter in their role as sedative agents. The increase in psychotropic polypharmacy suggests an ongoing 


\section{Psychotropic Dispensing in Dementia in Long-Term Care}

reliance on psychotropic usage in the management of patients with dementia in long-term care where provisions of nonpharmacological therapies are likely inadequate. In the absence of firm evidence from large-scale randomized controlled trials regarding the efficacy and safety of various psychotropics (including sedative antidepressants) for the treatment of NPS in the context of frail elderly with dementia in long-term care, this report represents an important contribution to research on a major public health concern.

This study was supported by the Institute for Clinical Evaluative Sciences (ICES) Western site. ICES is funded by an annual grant from the Ontario Ministry of Health and Long-Term Care (MOHLTC). Core funding for ICES Western is provided by the Academic Medical Organization of Southwestern Ontario (AMOSO), the Schulich School of Medicine and Dentistry (SSMD), Western University, and the Lawson Health Research Institute (LHRI). The lead author was supported by funds received from AMOSO and the Department of Psychiatry, Western. The opinions, results, and conclusions are those of the authors and are independent from the funding sources. No endorsement by ICES, AMOSO, SSMD, LHRI, Department of Psychiatry, or the MOHLTC is intended or should be inferred.

\section{References}

1. Rovner BW, Kafonek S, Filipp L, et al: Prevalence of mental illness in a community nursing home. Am J Psychiatry 1986; 143: $1446-1449$

2. Tariot PN, Podgorski CA, Blazina L, et al: Mental disorders in the nursing home: another perspective. Am J Psychiatry 1993; 150: $1063-1069$

3. Seitz D, Purandare N, Conn D: Prevalence of psychiatric disorders among older adults in long-term care homes: a systematic review. In Psychogeriatr 2010; 22:1025-1039

4. Selbaek G, Kirkevold O, Engedal K: The prevalence of psychiatric symptoms and behavioural disturbances and the use of psychotropic drugs in Norwegian nursing homes. Int J Geriatr Psychiatry 2007; 22:843-849

5. Sink KM, Holden KF, Yaffe K: Pharmacological treatment of neuropsychiatric symptoms of dementia: a review of the evidence. JAMA 2005; 293:596-608

6. Valiyeva E, Herrmann N, Rochon PA, et al: Effect of regulatory warnings on antipsychotic prescription rates among elderly patients with dementia: a population-based time-series analysis. CMAJ 2008; 179:438-446

7. Alessi-Severini S, Dahl M, Schultz J, et al: Prescribing of psychotropic medications to the elderly population of a Canadian province: a retrospective study using administrative databases. PeerJ 2013; 1:e168

8. Weekes LM: Senate committee recommendations for antipsychotic use in people with dementia. Med J Aust 2014; 200:438

9. NICE and SCIE (2006) Dementia: Supporting People with Dementia and their Carers in Health and Social Care. NICE clinical guideline 42. Available at www.nice.org.uk/CG42

10. Schneider LS, Dagerman KS, Insel P: Risk of death with atypical antipsychotic drug treatment for dementia: meta-analysis of randomized placebo-controlled trials. JAMA 2005; 294: $1934-1943$

11. Moore A, Patterson C, Lee L, et al: Fourth Canadian Consensus Conference on the Diagnosis and Treatment of Dementia: recommendations for family physicians. Can Fam Physician 2014; 60:433-438

12. Herrmann N, Lanctot KL, Hogan DB: Pharmacological recommendations for the symptomatic treatment of dementia: the Canadian Consensus Conference on the Diagnosis and Treatment of Dementia 2012. Alzheimers Res Ther 2013; 5:S5
13. TarjaL: Drug use among the home-dwelling elderly. Trends, polypharmacy and sedation, Oulu, Oulu, 2003. Available at http:// herkules.oulu.fi/isbn9514271025/isbn9514271025.pdf

14. Lovheim H, Sandman PO, Kallin K, et al: Relationship between antipsychotic drug use and behavioral and psychological symptoms of dementia in old people with cognitive impairment living in geriatric care. In Psychogeriatr 2006; 18:713-726

15. Chen Y, Briesacher BA, Field TS, et al: Unexplained variation across US nursing homes in antipsychotic prescribing rates. Arch Intern Med 2010; 170:89-95

16. Tartaglia MC, Hu B, Mehta K, et al: Demographic and neuropsychiatric factors associated with off-label medication use in frontotemporal dementia and Alzheimer's disease. Alzheimer Dis Assoc Disord 2014; 28:182-189

17. Barnes TR, Banerjee S, Collins N, et al: Antipsychotics in dementia: prevalence and quality of antipsychotic drug prescribing in UK mental health services. Br J Psychiatry 2012; 201: 221-226

18. Eichler T, Wucherer D, Thyrian JR, et al: Antipsychotic drug treatment in ambulatory dementia care: prevalence and correlates. J Alzheimers Dis 2015; 43(4):1303-1311

19. Martinez C, Jones RW, Rietbrock S: Trends in the prevalence of antipsychotic drug use among patients with Alzheimer's disease and other dementias including those treated with antidementia drugs in the community in the UK: a cohort study. BMJ Open 2013; 3(1); e002080. http://dx.doi.org/10.1136/bmjopen-2012002080

20. Bond M, Rogers G, Peters J, et al: The effectiveness and costeffectiveness of donepezil, galantamine, rivastigmine and memantine for the treatment of Alzheimer's disease (review of Technology Appraisal No. 111): a systematic review and economic model. Health Technol Assess 2012; 16:1-470

21. Hohl CM, Dankoff J, Colacone A, et al: Polypharmacy, adverse drug-related events, and potential adverse drug interactions in elderly patients presenting to an emergency department. Ann Emerg Med 2001; 38:666-671

22. Fereshtehnejad SM, Johnell K, Eriksdotter M: Anti-dementia drugs and co-medication among patients with Alzheimer's disease: investigating real-world drug use in clinical practice using the Swedish Dementia Quality Registry (SveDem). Drugs Aging 2014; $31: 215-224$ 
23. Kim HM, Chiang C, Weintraub D, et al: Treatment changes among older patients with dementia treated with antipsychotics. Int J Geriatr Psychiatry 2015 Mar 11. http://dx.doi.org/10.1002/ gps. 4281

24. Mate KE, Kerr KP, Pond D, et al: Impact of multiple low-level anticholinergic medications on anticholinergic load of community-dwelling elderly with and without dementia. Drugs Aging 2015; 32:159-167

25. Population Projections for Canada, Provinces and Territories 2009 to 2036. Stat Canada; available at http://www.statcan.gc.ca/ pub/91-520-x/91-520-x2010001-eng.pdf

26. Levy AR, O'Brien BJ, Sellors C, et al: Coding accuracy of administrative drug claims in the Ontario Drug Benefit database. Can J Clin Pharmacol 2003; 10:67-71

27. St Germaine-Smith C, Metcalfe A, Pringsheim T, et al: Recommendations for optimal ICD codes to study neurologic conditions: a systematic review. Neurology 2012; 79:1049-1055

28. Seitz DP, Gill SS, Bell CM, et al: Postoperative medical complications associated with anesthesia in older adults with dementia. J Am Geriatr Soc 2014; 62:2102-2109

29. Seitz DP, Gill SS, Gruneir A, et al: Effects of dementia on postoperative outcomes of older adults with hip fractures: a population-based study. J Am Med Dir Assoc 2014; 15:334-341

30. Quan H, Sundararajan V, Halfon P, et al: Coding algorithms for defining comorbidities in ICD-9-CM and ICD-10 administrative data. Med Care 2005; 43:1130-1139

31. Deyo RA, Cherkin DC, Ciol MA: Adapting a clinical comorbidity index for use with ICD-9-CM administrative databases. J Clin Epidemiol 1992; 45:613-619

32. Pindyck RS: Econometric Models and Economic Forecasts, Ed. 4. New York, Irwin McGraw-Hill, 1998

33. Dickey David A, Fuller Wayne A: Distribution of the estimators for autoregressive time series with a unit root. J Am Stat Assoc 1979:427-431

34. Ljung GM, Box GEP: On a measure of lack of fit in time series models. Biometrika 1978; 65:297-303

35. Norman MA, Whooley ME, Lee K. Depression and other mental health issues. In: Landefeld CS, Palmer RM, Johnson MA, Johnston $\mathrm{CB}$, Lyons WL, editors. Current geriatric diagnosis and treatment. New York: McGraw Hill; 2004. pp. 100-113

36. National Dementia and Antipsychotic Prescribing Audit National Summary Report. (online). Available http://www. hscic.gov.uk/searchcatalogue? productid $=7624 \& \mathrm{q}=$ title $\% 3 \mathrm{a} \% 22$ National+Dementia + and + Antipsychotic + Prescribing + Audits $\% 22$ $\&$ sort $=$ Relevance $\&$ size $=10 \&$ page $=1$-top. Accessed July 2012
37. McIntosh B, Clark M, Spry C: CADTH rapid response reports, in Benzodiazepines in Older Adults: A Review of Clinical Effectiveness, Cost-Effectiveness, and Guidelines. Ottawa, Canadian Agency for Drugs and Technologies in Health, 2011; available at https://www.cadth.ca/media/pdf/M0022_Benzodiazepines_in_ the_Elderly_L3_e.pdf

38. Banerjee S, Hellier J, Dewey M, et al: Sertraline or mirtazapine for depression in dementia (HTA-SADD): a randomised, multicentre, double-blind, placebo-controlled trial. Lancet 2011; 378: 403-411

39. Porsteinsson AP, Drye LT, Pollock BG, et al: Effect of citalopram on agitation in Alzheimer disease: the CitAD randomized clinical trial. JAMA 2014; 311:682-691

40. Cakir S, Kulaksizoglu IB: The efficacy of mirtazapine in agitated patients with Alzheimer's disease: A 12-week open-label pilot study. Neuropsychiatr Dis Treat 2008; 4:963-966

41. Camargos EF, Louzada LL, Quintas JL, et al: Trazodone improves sleep parameters in alzheimer disease patients: a randomized, double-blind, and placebo-controlled study. Am J Geriatr Psychiatry 2014; 22(12):1565-1574. http://dx.doi.org/10.1016/j.jagp. 2013.12.174. Epub 2014 Jan 4

42. Lebert F, Stekke W, Hasenbroekx C, et al: Frontotemporal dementia: a randomised, controlled trial with trazodone. Dement Geriatr Cogn Disord 2004; 17:355-359

43. Lai SW, Lin $\mathrm{CH}$, Liao $\mathrm{KF}$, et al: Association between polypharmacy and dementia in older people: a population-based case-control study in Taiwan. Geriatr Gerontol Int 2012; 12: 491-498

44. Kingsbury SJ, Yi D, Simpson GM: Psychopharmacology: rational and irrational polypharmacy. Psychiatr Serv 2001; 52 : $1033-1036$

45. Lemay CA, Mazor KM, Field TS, et al: Knowledge of and perceived need for evidence-based education about antipsychotic medications among nursing home leadership and staff. J Am Med Dir Assoc 2013; 14:895-900

46. Salloway S, Sperling R, Fox NC, et al: Two phase 3 trials of bapineuzumab in mild-to-moderate Alzheimer's disease. N Engl J Med 2014; 370:322-333

47. Cohen-Mansfield J, Thein K, Marx MS: Predictors of the impact of nonpharmacologic interventions for agitation in nursing home residents with advanced dementia. J Clin Psychiatry 2014; 75: e666-e671

48. Seitz DP, Gill SS: Review: non-pharmacological interventions delivered by family caregivers improve symptoms in people with dementia. Evid Based Ment Health 2013; 16:22 